\title{
COMET, TUNEL, and TEM analysis of an infertile male with short tail sperm
}

\author{
Ayşen Durmaz', Serap Cilaker Mıçılı², Seda Vatansever ${ }^{3}$, Cumhur Gündüz ${ }^{4}$, Hüsnü Alper Bağrıyanık², Nurten Dikmen ${ }^{5}$, \\ Ege Nazan Tavmergen Göker ${ }^{1}$, Erol Tavmergen ${ }^{1}$ \\ ${ }^{\prime}$ Family Planning Infertility Research and Treatment Center, Ege University, Izmir, Turkey \\ ${ }^{2}$ Department of Histology and Embryology, Dokuz Eylül University Faculty of Medicine, İmir, Turkey \\ ${ }^{3}$ Department of Histology and Embryology, Celal Bayar University Faculty of Medicine, Manisa, Turkey \\ ${ }^{4}$ Department of Medical Biology, Ege University Faculty of Medicine, Izmir, Turkey \\ ${ }^{5}$ Department of Medical Biochemistry, Çukurova University Faculty of Medicine, Adana, Turkey
}

\begin{abstract}
Male infertility is correlated with sperm morphology and sperm DNA damage, which are completely different from that of fertile individuals. An accurate sperm DNA damage analysis and ultrastructural examination of the ejaculate provide important support in the clinical evaluation. It is supposed that in the near future, the fertilization rate, pregnancy rate, and miscarriages could be predicted using the combination of these types of tests in assisted reproductive technologies (ARTs). For this purpose, we report a very rare case of an infertile man having short tail sperm. The infertile man and his wife underwent in vitro fertilization (IVF) with intracytoplasmic sperm injection (ICSI). During this process, we examined the ultrastructure of the ejaculated sperm with transmission electron microscopy (TEM) and calculated the sperm DNA damage with terminal deoxynucleotidyl transferase dUTP nick end labeling (TUNEL) and COMET assays. Then, we evaluated the association between sperm DNA damage and embryo quality. (J Turk Ger Gynecol Assoc 2015; 16: 54-7)
\end{abstract}

Keywords: Short tail sperm, sperm DNA damage, transmission electron microscopy

Received: 24 January, 2014

Accepted: 28 January, 2014

Available Online Date: 08 August, 2014

\section{Introduction}

Sperm chromatin structure and sperm DNA integrity are important parameters for successful fertilization, embryo development, and heritage of the genome to the next generation. Abnormal spermatozoa contain high levels of damaged DNA and reactive oxygen species (ROS); also, they show alterations in protamination, chromatin packaging, and depleted antioxidant profile. The cumulative effect is demonstrated as poor semen quality and poor reproductive outcome in infertile men $(1,2)$. We report here a very rare case of an infertile man who has short tail sperm. The infertile man and his wife underwent in vitro fertilization (IVF) with intracytoplasmic sperm injection (ICSI). During this process, we examined the ultrastructure of the ejaculated sperm with transmission electron microscopy (TEM) and calculated the sperm DNA damage with terminal deoxynucleotidyl transferase dUTP nick end labeling (TUNEL) and COMET assays. Then, we evaluated the association between sperm DNA damage and embryo quality.

\section{Case Presentation}

A 39-year-old Turkish male gold mine worker was referred to Ege University Family Planning and Infertility Research and
Treatment Center for evaluation of infertility associated with severe asthenoteratozoospermia. The patient and his wife had not achieved a pregnancy for 18 years of unprotected coitus. He reported that he had been smoking 10 cigarettes a day for the last 10 years and he did not drink alcohol. He has 2 sisters who have children. He does not have any brothers but has 2 male cousins (his uncle's son) who could not have any children either. Our patient does not have any idea whether the cousins received any treatment for in vitro fertilization. The lymphocyte karyotype of the patient was 46; XY and Y chromosome microdeletion was not detected. The lymphocyte karyotype of his wife was 46,XX. The wife's clinical and biological analysis did not reveal anything particular except her age (40 years old). Microbiological investigations did not show any urogenital infection.

The patient was involved in this study within the framework of decision \# 5 of the Ethics Committee of Çukurova University Faculty of Medicine, dated June 12, 2007. He was informed about the study and gave written permission for the analysis related to the study.

A semen sample was collected by masturbation after 4 days of sexual abstinence. The ejaculate was fully liquefied, and the semen analysis was performed in our laboratory according to standard World Health Organization (WHO) criteria. 


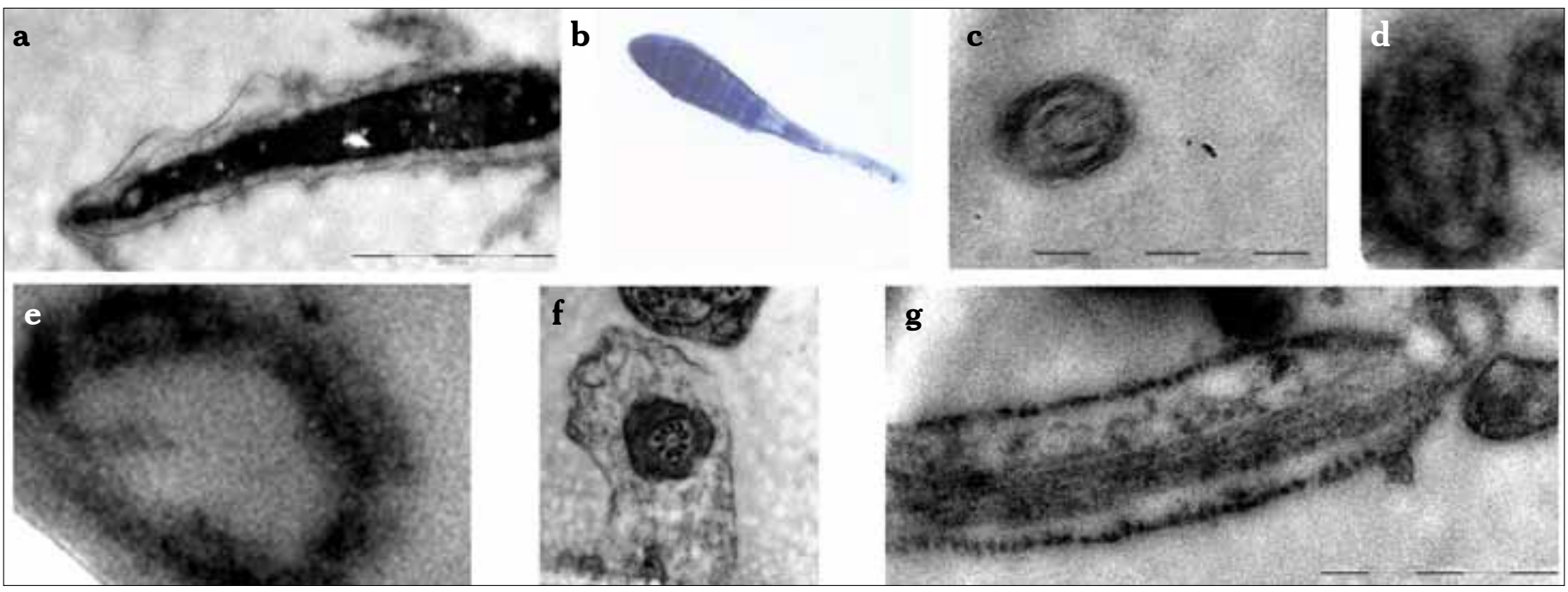

Figure 1. a-g. Transmission electron microscopy (TEM) micrograph of a longitudinal section of a sperm head showing a normal acrosome and nucleus structure. A: Acrosome, N: Nucleus (a). Semi-thin section with stained Toluidine blue and examined by light microscopy. Short tails were observed compared the long head (b). TEM micrographs of cross-sections of tails: the fibrous sheath was disorganized and the axoneme and outer dense fibers were missed (black arrow) (c-e). Fibrous sheath was disorganized (asterisk) and outer dense fibers are disorganized (white arrow) (f). TEM micrographs of cross-sections of tails at midpiece: microtubules were disorganized (Mt), and the head and neck junction had irregular and incomplete cytoplasm (IS) (g) (Bars: a, c, d, e, f, g: 5000 nm, b:X100)

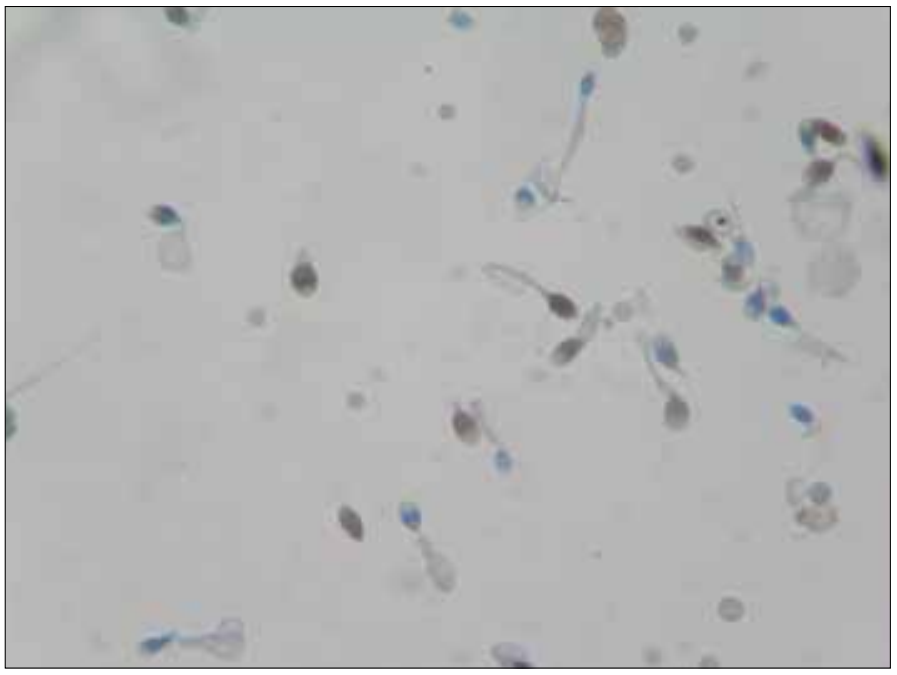

Figure 2. TUNEL-positive sperm was detected as a brown precipitate in the head of the sperm after TUNEL assay. Scale bar: $25 \mu \mathrm{m}$

After semen analyses, the sample was divided into three groups for ultrastructural sperm evaluation using the TEM, TUNEL, and COMET assays.

After light microscopic evaluation, semen parameters revealed an asthenoteratozoospermia profile (sperm count: $15 \times 10^{6} / \mathrm{mL}$ ), with $90 \%$ of spermatozoa being immotile and $10 \%$ of spermatozoa only just moving slightly; there was no progressive motility. Morphology analysis revealed teratozoospermia, with all spermatozoa showing abnormal head morphology and 85\% with a short tail phenotype. Eosin staining revealed that $70 \%$ of the sperm cells were alive.

After electron microscopic analysis, the sperm heads were observed to have a normal acrosomal structure and cell nucleus. The junction of the head and neck on the transverse section was

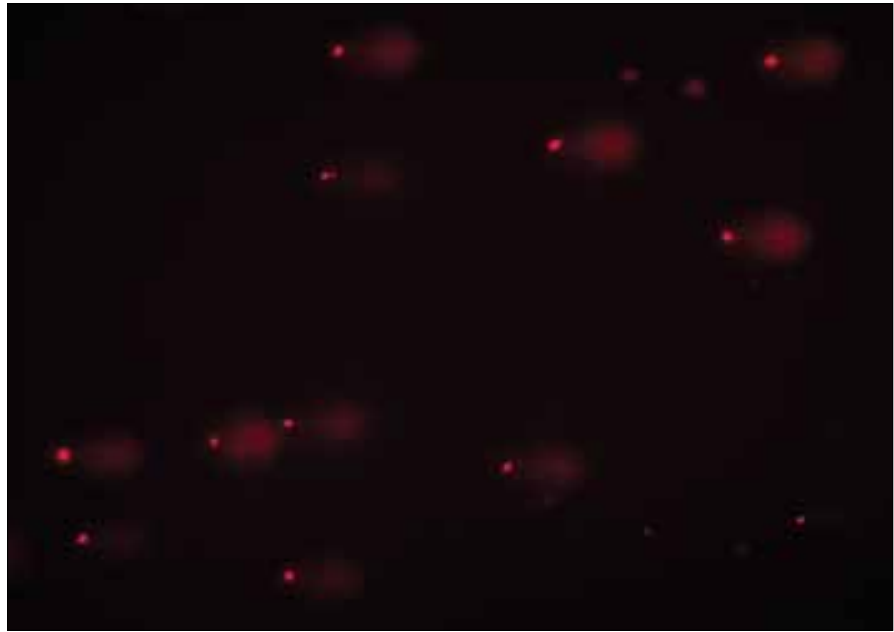

Figure 3. DNA damage in sperm as measured by the Comet assay. Scale bar: $25 \mu \mathrm{m}$

irregular, and the cytoplasmic microtubules were missing and disorganized. Deficiencies in the structure of the cross-sections were examined axoneme queues, and the mitochondrial fibrous sheath was found to be irregular. Irregular structure of mitochondria was observed in the midpiece of the tail (Figure 1).

After TUNEL analyses, the TUNEL-positive cells were detected as brown precipitates in the heads of the sperm (Figure 2), and the percentage of the TUNEL-positive sperm was $59.5 \%$. The mean level of DNA fragmentation is $13.1 \pm 7.3 \%$ in fertile individuals (Table 1) (3).

Results of the Comet assay showed an index of damaged DNA (percentage tail DNA) and undamaged DNA (percentage head DNA). In this case, the patient's sperm DNA damage was calculated as 59.15\% and is shown in Figure 3. At present, clini- 


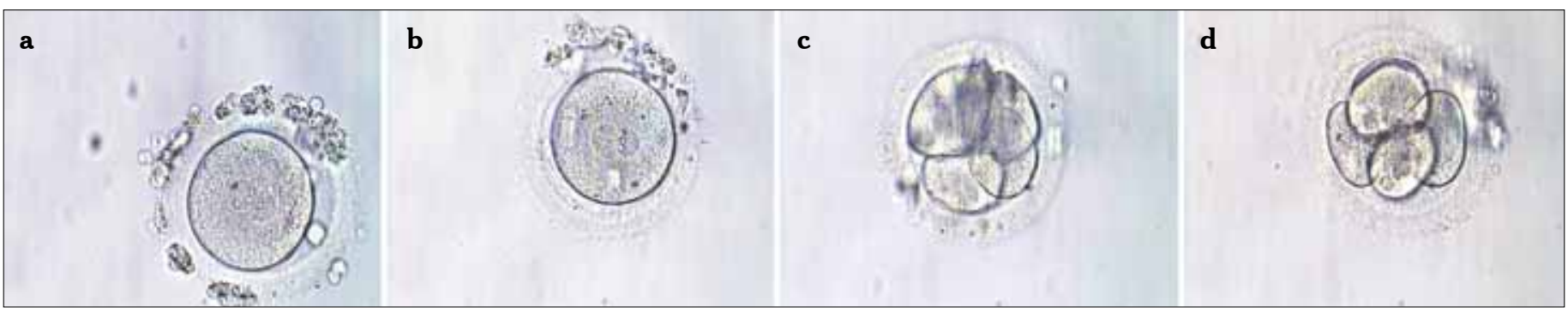

Figure 4. a-d. Diploid zygote (2PN) (a). Triploid zygote (3PN) (b). Day 2 embryo that was transferred (c). Day 2 embryo that was transferred (d)

Table 1. Sperm DNA damage analysis with TUNEL and COMET assays

\begin{tabular}{|c|c|c|}
\hline & $\begin{array}{c}\text { COMET Assay } \\
\text { (Percentage tail DNA) }\end{array}$ & $\begin{array}{l}\text { TUNEL Assay } \\
\text { (\%) }\end{array}$ \\
\hline $\begin{array}{l}\text { Normospermic } \\
\text { volunteers }\end{array}$ & $7.21 \pm 7.51$ & $13.10 \pm 7.30$ \\
\hline Case with short tail & 59.15 & 59.50 \\
\hline
\end{tabular}

cally useful thresholds have not been established for sperm DNA damage analysis using the Comet assay. So, each laboratory has established its own normal values. According to our previous study, which was unpublished and consisted of 20 normospermic fertile men, the mean percentage of damaged DNA in the normospermic group was calculated as $7.21 \pm 7.51 \%$ (Table 1 ).

\section{IVF}

Due to the severe asthenoteratozoospermia and high DNA damage, the couple underwent IVF with ICSI. Six oocytes were picked from his wife on day 0 , and all oocytes were mature (MII). During the ICSI procedure, we preferred ejaculated spermatozoa that moved slightly and had long tails. After 16-18 hours from microinjection, fertilization check was performed, and 5 of them had two pronuclei (2PN) (Figure 4a). The other one had three pronuclei; so, it was evaluated as 3PN (Figure 4b). On the second day after microinjection, cleavage was observed in all embryos, although their grades were poor. The two embryos (Figure 4c, d) were transferred on day 2, but pregnancy did not occur because of low levels of $\beta$ hCG after 15 days of transfer.

\section{Discussion}

The mammalian flagellum is composed of a number of cytoskeletal elements whose proper assembly is critical for sperm motility. These elements are the axoneme, outer dense fibers, and fibrous sheath, which are essential for flagellar development and movement $(4,5)$. In this case, ultrastructural analysis of the sperm showed that the fibrous sheath in the midpiece and principal piece was irregular. Due to this defect, sperm motility was decreased, and it was recorded around $10 \%$.

Sperm DNA integrity and sperm morphology are essential parameters for successful fertilization and embryogenesis. According to the electron microscopic evaluation, the sperm heads were observed to have a normal acrosomal structure and cell nucleus.
But, the sperm DNA damage was calculated as $59.5 \%$ and $59.15 \%$ with the TUNEL and COMET assays, respectively. Because of the normal structure of the sperm heads, DNA damage can not prevent the pronuclei formation. However, it is clear that severe asthenoteratozoospermia has a positive correlation with increased sperm DNA damage, which is detected with the TUNEL and COMET assays, which were correlated to each other, consequently affecting embryo quality and pregnancy negatively. These results are strengthening the previous findings that claimed that DNA-damaged sperm can form pronuclei at fertilization (6) and allow for normal embryo development (7). But, the risk of failure to achieve a pregnancy increases when the sperm DNA fragmentation exceeds the value of $52 \%$ by alkaline Comet assay (8).

A negative pregnancy result does not essentially depend on the paternal genome. Oocytes also have to be considered. Human oocytes have the capacity to repair paternal DNA abnormalities. This capacity is largely based on its cytoplasmic and genomic quality but also on age, ovarian environment, and fertility level. However, this capability deteriorates with age. When this repair tool is not adequate, embryonic genome activation may fail. At this point, development of the embryo may end, and blastocyst formation may not be achieved.

In our case, due to the highly damaged sperm DNA and advanced age of the wife ( 40 years old), the capacity of the oocytes to repair was not sufficient; thus, the pregnancy was deteriorated.

Ethics Committee Approval: Ethics committee approval was received for this study from the ethics committee of Çukurova University.

Informed Consent: Written informed consent was obtained from patient who participated in this case.

Peer-review: Externally peer-reviewed.

Author contributions: Concept - A.D., S.V.; Design - A.D., C.G., N.D.; Supervision - E.T., E.N.T.G., N.D.; Materials - A.D., N.D., C.G.; Data Collection\&/or Processing - A.D., S.M., E.T.; Analysis\&/or Interpretation A.D., S.M., H.A.B.; Literature Search - A.D., S.V.; Writing - A.D., E.N.T.G., E.T.; Critical Reviews - A.D., S.M., H.A.B.

Conflict of Interest: No conflict of interest was declared by the authors. Financial Disclosure: This study was supported by Çukurova University Research Foundation (TF2007D8).

\section{References}

1. Simon L, Proutski I, Stevenson M, Jennings D, McManus J, Lutton D, Lewis SEM. Sperm DNA damage has a negative association with live-birth rates after IVF. Reprod Biomed Online 2013; 26: 68-78. [CrossRef] 
2. Shamsi MB, Venkatesh S, Tanwar M, Talwar P, Sharma RK, Dhawan A, et al. DNA integrity and semen quality in men with low seminal antioxidant levels. Mutat Res 2009; 665: 29-36. [CrossRef]

3. Sergerie M, Laforest G, Bujan L, Bissonnette F, Bleau G. Sperm DNA fragmentation: Threshold value in male fertility. Hum Reprod 2005: 20: 3446-51. [CrossRef]

4. Bacceti B, Bruni E, Gambera L, Moretti M, Piombon P. An ultrastructural and immunocytochemical study of a rare genetic sperm tail defect that causes infertility in humans. Fertil Steril 2004; 82: 463-8. [CrossRef]

5. Turner RM, Foster JA, Gerton GL, Moss SB, Patrizio P. Molecular evaluation of two major human sperm fibrous sheath proteins, pro-hAKAP82 and hAKAP82, in stump tail sperm. Fertil Steril 2001; 76: 267-74. [CrossRef]
6. Twigg JP, Irvine DS, Aitken RJ. Oxidative damage to DNA in human spermatozoa does not preclude pronucleus formation at intracytoplasmic sperm injection. Hum Reprod 1998; 13: 1864-71. [CrossRef]

7. Bungum M, Humaidan P, Spano M, Jepson K, Bungum L, Giwercman A. The predictive value of sperm chromatin structure assay (SCSA) parameters for the outcome of intrauterine insemination, IVF and ICSI. Hum Reprod 2004; 19: 1401-8. [CrossRef]

8. Simon L, Lutton D, McManus J, Lewis SEM. Sperm DNA damage measured by the alkaline Comet assay as an independent predictor of male infertility and in vitro fertilization success. Fertil Steril 2011; 95: 652-7. [CrossRef] 